$$
\begin{gathered}
54 N 095-22106 \\
\text { CONF- } 960376--8
\end{gathered}
$$

\title{
SUPERCRITICAL CARBON DIOXIDE EXTRACTION OF SOLVENT FROM MICROMACHINED STRUCTURES*
}

\author{
Edward M. Russick, Carol L. J. Adkins, Christopher W. Dyck \\ Sandia National Laboratories, \\ Albuquerque, NM 87185

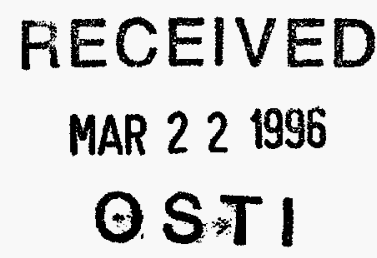

\begin{abstract}
We have demonstrated that supercritical carbon dioxide extraction can be used for solvent removal to successfully release compliant surface micromachined structures on silicon wafers developed at Sandia National Laboratories. Structures that have been successfully extracted and released include single gear microengines, bridge and cantilever beams, pressure transducers, and experimental comb drive actuators. Since the supercritical fluid has negligible surface tension, it has virtually unabated access to solvent residing in capillary-like spaces as narrow as 1-3 $\mu \mathrm{m}$ under the micromachined features. While conventional drying techniques have been plagued with the collapse and sticking of micromachined structures due to surface tension effects, supercritical carbon dioxide has been shown to reproducibly dry components and test structures, including bridge and cantilever beams approaching $1000 \mu \mathrm{m}$ in length, without collapsing. The equipment and the extraction process are described, and photographs of supercritically dried test structures and components are presented.
\end{abstract}

\section{DISCLAIMER}

This report was prepared as an account of work sponsored by an agency of the United States Government. Neither the United States Government nor any agency thereof, nor any of their employees, makes any warranty, express or implied, or assumes any legal liability or responsibility for the accuracy, completeness, or usefulness of any information, apparatus, product, or process disclosed, or represents that its use would not infringe privately owned rights. Reference herein to any specific commercial product; process, or service by trade name, trademark, manufacturer, or otherwise does not necessarily constitute or imply its endorsement, recommendation, or favoring by the United States Government or any agency thereof. The views and opinions of authors expressed herein do not necessarily state or reflect those of the United States Government or any agency thereof.

\section{DISTRIBUTION OF THIS DOCLAEMT IS UALIMTED}<smiles>[Mg][Mg]</smiles>

*This work was performed at Sandia National Laboratories under U.S. Department of Energy contract No. DE-AC04-94AL85000. 


\section{INTRODUCTION}

With the trend towards miniaturization of microprocessors in the electronics industry, it seems appropriate that the development of miniature electromechanical components should be of interest as well. In fact, surface micromachining of polysilicon films deposited on silicon wafers is an emerging technology in the fabrication of microactuators and microsensors ${ }^{1}$. These miniaturized components include microengines, microlever actuators, accelerometers, and pressure sensors which have potential uses in a variety of applications for mechanical and electrical devices both in industry and in government research (e.g., weapons design). Only surface micromachined structures are discussed, which involve the deposition and patterning of films above the surface of the silicon substrate ${ }^{2}$. Bulk micromachining, which involves the removal of the substrate to define features ${ }^{3}$ will not be discussed in this paper.

Surface machined microstructures are formed using a combination of masking, dry plasma etching of polysilicon film deposited on the wafer, and wet etching done in a liquidphase acid solution such as hydrofluoric acid (HF). Figure 1 illustrates the basic surface micromachining process. The final HF etch is followed by a water rinse. In some cases the HF etch is followed by an ammonium fluoride $\left(\mathrm{NH}_{4} \mathrm{~F}\right)$ treatment ${ }^{4}$, to be discussed later, which may increase the long term reliability of the micromachined parts. After etching and rinsing, the part are dried to yield the released micromachined sample. It is to the drying process that we have applied supercritical fluid extraction technology.

A scanning electron micrograph of a microengine is shown in Figure 2. Microengines are multi-layer structures that are fabricated by repeating surface micromachining process in a series of successive layers ${ }^{1}$. It can be seen that the many intricate features of the microengine have been formed on the silicon wafer in an area of only about 4 square millimeters. The function of the microengine is to drive a microgear, thus performing mechanical work at a microscopic scale. The microengine is driven by an alternating electrical bias applied to comb drive actuators whose motion is translated to the microgear. The microgear could serve as a spinning portion of a gyroscope or be used to control optical shutters and mirrors. Microlever actuators also are designed to perform work on a very small scale, but with a different mechanical design. With an arrangement of lever arms and fulcrums, the movement of the drive mechanism is increased such that slight motion at the drive is greatly increased at the working part. A micromachined accelerometer is essentially a suspended silicon plate, fixed to sidewalls by silicon springs, which is placed under an electrical bias. During acceleration, the plate will attempt to deflect, changing the bias required between the plate and the ground polysilicon plane to maintain the plate's equilibrium position. Acceleration is detected by the change in the bias. Micromachined pressure sensors consist of vacuum sealed cavities under diaphrams that deflects according to an applied pressure. Pressure measurement is accomplished with piezoresistors on the surface of the diaphram. Micrographs of these microstructures will be presented later in the results section.

Silicon is a very practical micromechanical material in that it is capable of a great amount of flexibility before fracturing. However, the compliant nature of the silicon makes it susceptible to fabrication problems. A significant problem in the fabrication of the micromachined components is sticking of released structures to the substrate after they are dried using conventional air drying techniques. The sticking, combined with static friction which these parts experience has been termed stiction, a phenomenon commonly seen in magnetic storage media ${ }^{5}$.

A number of phenomena may potentially cause microdynamic stiction of suspended microstructures, several of which will be identified here. Electrostatic forces due to electrostatic charging may cause sticking of micromachined structures. These forces can be generated on the wafer due to etching, rinsing and drying ${ }^{6}$. This is a non-equilibrium condition which usually dissipates over time or with contact between conducting surfaces. Second, a smooth surface finish may cause stiction. Smooth surfaces are more likely to 
stick, while surface roughness effectively increases the nominal separation between micromachined surfaces. Slight roughness on adjacent surfaces can reduce adhesion forces by several orders of magnitude ${ }^{7}$. The surfaces of the polysilicon microstructures usually have a microscopically textured surface after etching, possibly due to the orientation of the grain structure of the polysilicon as it was deposited and etched. Physical alteration of contacting surfaces through dry plasma etching has also been reported ${ }^{8}$. $\mathrm{NH}_{4} \mathrm{~F}$ etching, mentioned previously, has been demonstrated to slightly roughen the solid surfaces of the silicon surfaces. This may have a positive effect by inhibiting surface stiction and increasing the long term reliability of the microstructure. Third, a phenomenon called solid bridging ${ }^{6}$ occurs when non-volatile impurities present in the drying liquid are deposited on the surfaces of the microstructures. The impurities in narrow gaps formed by the suspended microstructures essentially bridge the gaps, causing the structures to stick. Obviously, avoiding impurities in the rinse liquid would help to minimize solid bridging.

Perhaps the most troublesome cause of surface stiction is liquid bridging ${ }^{6}$. Liquid bridging is due to the surface tension effects of trapped capillary liquids upon drying. The liquid, usually water, used to rinse the microstructures is trapped in the narrow gaps between the silicon wafer and the suspended structures. Interfacial forces generated when the trapped capillary fluid dries can cause the microstructures to collapse and stick. Figure 3 shows a comparison of a stuck pressure sensor with one that has been successfully released. The meniscus force between two flat, polished surfaces with a liquid bridge is given by ${ }^{5}$ :

$$
F_{m}=\frac{\gamma A}{h}\left(\cos \theta_{1}+\cos \theta_{2}\right)
$$

where $\theta_{1}$ and $\theta_{2}$ are the contact angles of the liquid with the two solid surfaces, $A$ is the shared area of the parallel surfaces, assuming the gap between them is flooded with capillary liquid, $h$ is the average thickness of the liquid bridge, and $\gamma$ is surface tension, 73 dynes/cm for water. Obviously, reduction or elimination of surface tension will lessen or eliminate surface stiction due to liquid bridging.

In this paper results demonstrate that supercritical carbon dioxide $\left(\mathrm{SCCO}_{2}\right)$ extraction can be used to remove capillary liquids (e.g. methanol) from micromachined structures, eliminating sticking caused by surface tension effects. Carbon dioxide has long been known to be a good solvent for many organic compounds ${ }^{9}$, and methanol specifically is known to be very soluble in $\mathrm{SCCO}_{2}{ }^{10}$. After the methanol has been dissolved and carried away by the supercritical fluid, the vessel is depressurized to yield dry, released microstructures. Surface tension effects have been eliminated since $\mathrm{SCCO}_{2}$ has negligible surface tension like a gas. Furthermore, $\mathrm{SCCO}_{2}$ possesses gas-like properties of diffusivity and viscosity ${ }^{11}$ which allow the supercritical fluid to access narrow gaps under the microfeatures for removal of trapped capillary fluid. Except for approximate success or failure rates, statistical analysis of the results are not included since the intention of this paper was simply to demonstrate the feasibility of applying this technique to the manufacture of surface micromachined devices. In fact, supercritical extraction of solvent from these devices has been so successful that it has been incorporated into the micromechanics fabrication process at Sandia National Laboratories.

It should be noted that this work has been preceded by other successful applications of supercritical fluid extraction technology to eliminate surface tension effects. This includes the extraction of solvents from phase-separated polymer gels to produce microcellular foams ${ }^{12}$, and the extraction of solvents from silica aerogels ${ }^{13}$. Also, researchers at the University of California at Berkeley have removed solvent from micromachined samples using liquid carbon dioxide ${ }^{14}$ which requires the additional step of increasing to supercritical conditions before depressurizing to avoid the sticking problems caused by a liquid/vapor interface. 


\section{EXPERIMENTAL}

Description of pressure equipment

The extraction of methanol from micromachined samples was performed in a $\mathrm{SCCO}_{2}$ pressure system, rated at 5000 psi maximum allowable working pressure, which is depicted schematically in Figure 4. The $\mathrm{CO}_{2}$ source gas is supplied by three size $1 \mathrm{~A}$ cylinders of technical grade $\mathrm{CO}_{2}$ (Trigas, Albuquerque, NM) which is delivered through a regulator, to a pneumatic compressor (Gas Booster, model AGD-30, Haskel Corp., Burbank, CA). The compressor allows for pressurization above the critical point for $\mathrm{CO}_{2}$. The gas flows through a 0.5 micron sintered stainless steel filter, into a one liter temperature-controlled extraction vessel (Thar Designs, Pittsburgh, PA). Temperature control is provided by a constant temperature circulating bath which flows heat transfer fluid through a water jacket surrounding the outer wall of the vessel. After leaving the extraction vessel, the $\mathrm{CO}_{2}$ flows through a high pressure metering valve (High Pressure Equipment Co., Erie, PA) through which the pressure is reduced. The metering valve is warmed with heat tape to prevent clogging the valve with dry ice that might otherwise be formed due to Joule-Thomson cooling upon expansion of the gas. The pressure is reduced into a temperature controlled $500 \mathrm{ml}$ cyclone separator recovery vessel (Thar Designs) held at $0^{\circ} \mathrm{C}$. Methanol is not as soluble in gaseous $\mathrm{CO}_{2}$ as in $\mathrm{SCCO}_{2}$, so the solvent condenses and can be trapped in the separator vessel. Finally, the gas is vented out of the laboratory through a suction duct. System pressure is monitored and controlled with a modular pressure controller with digital read-out (Autoclave Engineers, Erie, PA) which controls the pneumatic compressor to maintain the desired system pressure. Over-pressure protection is provided by a 5000 psi burst disc. All tubing is 1/4 inch O.D. (0.065" wall thickness) 316 stainless steel tubing. Tube fittings are 316SS Swagelok.

The extraction vessel is made of 17-4 PH stainless steel, has an inside diameter of 3 inches and inside length of approximately 8 inches. The inside of the vessel is accessed through end caps. The vessel is supported horizontally. To minimize excess vessel volume and to support the silicon wafer pieces being extracted, two aluminum halfcylinders were machined to effectively fill the entire vessel volume. At the intersection of the half-cylinders, a $2 \frac{1}{2}$ inch wide $\mathrm{x} / 8$ inch high channel was machined to allow for $\mathrm{CO}_{2}$ flow over the samples. On the bottom half-cylinder on which the wafer pieces rest, a 0.2 inch deep trough was milled to serve as a reservoir for the methanol. At the bottom of the trough are milled three rows of nine, square sample compartments that are approximately 0.775 inches on a side by approximately 0.04 inches deep which serve to keep the wafer pieces from inadvertently sliding on top of each other during the extraction. With the aluminum vessel inserts installed, the 1 liter vessel is reduced to an effective volume of about $190 \mathrm{ml}$. This arrangement forces $\mathrm{CO}_{2}$ to flow in more direct contact with the methanol being extracted from the micromachined samples.

\section{Experimental Procedure for Extraction of Methanol from Micromachined Structures}

Surface micromachined structures were release etched, rinsed in water, then exchanged with methanol as previously described. The microstructures used in our tests were an assortment of microengines, microlevers, accelerometers, pressure sensors, and also cantilever and bridge test structures.

Control samples were allowed to air dry; that is, methanol removal was achieved through evaporation at ambient temperature. This is the method commonly used to dry micromachined parts. Test samples were supercritically extracted with carbon dioxide as follows. The micromachined samples were transfered from a methanol bath to the sample trough in the aluminum vessel insert which contained approximately $20 \mathrm{ml}$ of methanol. The inserts with samples were loaded into the vessel, which was closed and then pressurized with $\mathrm{CO}_{2}$. Pressurization typically took between 15 and 20 minutes. 
Extraction time was typically 30 minutes, which was empirically determined to be a sufficient amount of time to totally remove the methanol. The mass flow rate for $\mathrm{CO}_{2}$, measured gravimetrically from the supply bottles, was approximately $30 \mathrm{~g} / \mathrm{min}$. After the extraction, the vessel was depressurized, usually within about 15-20 minutes. The samples were then removed from the extraction vessel.

Samples were extracted under three different sets of supercritical conditions. These are $1500 \mathrm{psi}, 40^{\circ} \mathrm{C}\left(\rho_{\mathrm{CO} 2}=0.65 \mathrm{~g} / \mathrm{ml}\right), 2300 \mathrm{psi}, 40^{\circ} \mathrm{C}\left(\rho_{\mathrm{CO}_{2}}=0.79 \mathrm{~g} / \mathrm{ml}\right)$, and $3000 \mathrm{psi}$, $40^{\circ} \mathrm{C}\left(\rho_{\mathrm{CO} 2}=0.85 \mathrm{~g} / \mathrm{ml}\right)$. These conditions were chosen to achieve supercritical fluid densities lower than, equal to, and greater than that of methanol $(0.79 \mathrm{~g} / \mathrm{ml})$. After methanol removal, control and test samples were observed and compared using scanning electron microscopy (SEM). When applicable (e.g. microengines), an electrical bias was applied to the microstructures in an attempt to make them work.

\section{RESULTS AND DISCUSSION}

\section{Comparison of Supercritical Carbon Dioxide Extraction with Conventional Air Drying}

Supercritical carbon dioxide was demonstrated to reliably extract methanol from all the tested microstructures without sticking due to surface tension effects. In contrast, approximately $90 \%$ of the air dried parts were stuck overall. For some samples that were supercritically extracted, fabrication problems, such as incomplete etches, were uncovered that had previously been masked by the sticking problems experienced with conventional air drying.

Almost $100 \%$ of the $\mathrm{SCCO}_{2}$ extracted microengines were free from sticking compared to only a $10 \%$ success rate for air-dried microengines. Surface stiction was observed in the springs that support the comb drive actuators. Upon sticking, the springs inhibit the movement of the comb drives, rendering the microengine useless. A micrograph comparison of a stuck air-dried microengine spring with that of a successfully released $\mathrm{SCCO}_{2}$ extracted microengine is shown in Figure 5.

Similar results were seen with microlever actuators with nearly $100 \%$ success with supercritical drying as opposed to nearly $100 \%$ failure rate with air drying. Figure 6 shows a micrograph of a microlever actuator with higher magnifications of a stuck air dried lever compared to a released lever that was $\mathrm{SCCO}_{2}$ extracted.

Accelerometer stiction was not visually obvious using SEM. To test for stiction, electrostatic deflection of the plate from its equilibrium position was measured. By recording the voltage necessary to deflect the plate, a relative measure of the effectiveness of the release was made. For air drying, nearly all accelerometers were stuck and did not deflect electrostatically. All accelerometers that were $\mathrm{SCCO}_{2}$ extracted were free and unstuck. In subsequent deflection attempts, some of the accelerometers did show signs of sticking. This is believed to be a processing phenomenon not related to the $\mathrm{SCCO}_{2}$ cleaning since the devices were fully released immediately after the $\mathrm{SCCO}_{2}$ extraction. It is possible with sufficient humidity that condensation of water on the micromachined surfaces may have caused stiction after solvent removal. $\mathrm{NH}_{4} \mathrm{~F}$ etching before drying to slightly roughen the solid surfaces may help to increase the long term reliablility of the accelerometers. Micrographs of a supercritically extracted accelerometer are shown in Figure 7.

Pressure sensors above $200 \mu \mathrm{m}$ in diameter were usually stuck to the substrate after a standard release and air dry. $\mathrm{SCCO}_{2}$ extraction has produced freed structures up to 500 $\mu \mathrm{m}$, the maximum size that was attempted.

Bridge and cantilever test structures were $\mathrm{SCCO}_{2}$ extracted usually without surface stiction. For bridge structures, which are supported at both ends, beam lengths of up to 1.5 millimeters $(\mathrm{mm})$ were fully released. For air dried bridges, most under $1 \mathrm{~mm}$ were 
released and bridges from 1 to $1.5 \mathrm{~mm}$ had mixed results with some released and some stuck. Overall, $\mathrm{SCCO}_{2}$ performed considerably better than air drying for bridge structures.

Because cantilever test structures are anchored only at one end, they are generally more compliant than bridges. Cantilever beam widths of 10 and 20 microns, each with 2 micron thickness were dryed using both techniques for lengths up to 500 microns. Typically, cantilevers above 150-200 microns in length were stuck for both widths using standard air drying. Virtually all cantilever beams up to 500 microns were fully released using $\mathrm{SCCO}_{2}$ extraction. A comparison of air dried and $\mathrm{SCCO}_{2}$ extracted cantilever test structures is shown in Figure 8. It was found that any sticking of beams observed after $\mathrm{SCCO}_{2}$ drying was invariably caused by electrostatic forces generated by the electron beam in the SEM. If fact, supercritically extracted cantilever beams of $1 \mathrm{~mm}$ in length were observed to be consistently released when viewed with a light microscope.

\section{Effects of Supercritical Carbon Dioxide Density on Methanol Extraction Time}

Samples were successfully extracted with $\mathrm{SCCO}_{2}$ at all three sets of supercritical conditions that were attempted $\left(1500 \mathrm{psi}, 40.0^{\circ} \mathrm{C} ; 2300 \mathrm{psi}, 40.0^{\circ} \mathrm{C} ; 3000 \mathrm{psi}, 40.0^{\circ} \mathrm{C}\right)$. There was a noticeable difference, however, in the amount of time required to remove methanol from microstructures at the lowest pressure/density conditions, $1500 \mathrm{psi}, 40.0^{\circ} \mathrm{C}$ $\left(\rho_{\mathrm{CO} 2}=0.65 \mathrm{~g} / \mathrm{ml}\right)$. In most cases under these conditions, the typical 30 minute extraction time was insufficient to remove all the methanol from the solvent reservior in the vessel insert. In instances where microstructures were stuck, it was believed that surface tension effects of the remaining methanol drying from the gaps under the microstructures caused the surface stiction.

It is believed that both methanol solubility and the density difference between methanol and $\mathrm{SCCO}_{2}$ affect the rate at which the solvent is carried away from the solvent reservoir. While it has already been established that methanol is very soluble in $\mathrm{SCCO}_{2}$, at supercritical fluid densities lower than that of methanol, it may take longer for the $\mathrm{SCCO}_{2}$ to solubilize the solvent since the lower density extraction fluid does not easily displace the standing pool of methanol. At supercritical conditions which match or exceed the methanol density, the methanol/SCCO${ }_{2}$ interface may be more easily broken and the solvent displaced and solubilized. Methanol trapped under the micromachined structures can then be removed due to the gas-like diffusivity of the supercritical fluid which can access the narrow gaps to displace and dissolve the solvent. Higher, more turbulent $\mathrm{SCCO}_{2}$ flow rates may be required to overcome the interfacial energy of methanol and decrease extraction times at the lower density conditions.

\section{CONCLUSIONS}

We have demonstrated that supercritical carbon dioxide extraction can be used to remove methanol to release compliant surface micromachined structures on silicon wafers. $\mathrm{SCCO}_{2}$ extraction released virtually all samples of a variety of microcomponents and test structures. This is a vast improvement over conventional air drying which has a failure rate, due to surface stiction, of up to $90 \%$.

It was also shown that extraction times of shorter duration were required when supercritical fluid densities which matched or exceeded that of the liquid solvent (e.g., methanol) were used. It is believed this occurs since a higher density extraction fluid is more effective at displacing the liquid solvent, overcoming its interfacial energy, thereby enhancing the dissolution and solvent removal properties of the supercritical fluid.

At Sandia National Laboratories, $\mathrm{SCCO}_{2}$ is being used to remove solvent from surface micromachined devices on a small scale production basis. A new pressure system is being designed which, when installed in the microelectronics fabrication laboratory, will 
be used for larger scale supercritical extraction of solvent from compliant surface micromachined silicon wafer samples.

\section{ACKNOWLEDGMENTS}

The authors wish to acknowledge the contributions of Pat Shea who performed the SEM analysis. Micromechanical parts were supplied by William P. Eaton, Carole C. Barron, Jeff J. Sniegowski, and James H. Smith. This work was performed at Sandia National Laboratories under U.S. Department of Energy contract No. DE-AC0494AL85000.

\section{REFERENCES}

1. $\quad$ R. S. Muller, Sensors and Actuators, A21 (1990) 1-8.

2. R. T. Howe, J. Vac. Sci. Technology, 6 (1988) 1809-1813.

3. K. E. Peterson, Proc. IEEE, 70 (1982) 420-457.

4. M. R. Houston, R. Maboudiank and R. T. Howe, Digest of Technical Papers, 1995 International Conference on Solid-State Sensors and Actuators, Transducers '95, paper 45 (1995).

5. B. Bhushan, Tribology and Mechanics of Magnetic Storage Devices, SpringerVerlag, New York (1990).

6. R. L. Alley, G. J. Cuan, R. T. Howe, and K. Komvopoulos, Technical Digest: IEEE Solid State Sensor and Actuator Workshop, Hilton Head (1992) 202-207.

7. J. Czarnecki, and T. Dabros, J. Coll. Interf. Sci., 78 (1980) 25-30.

8. Y. Yee, K. Chun, and J. D. Lee, Digest of Technical Papers, 1995 International Conference on Solid State Actuators, Transducers '95, paper 44 (1995).

9. A. W. Francis, J.Phys. Chem., 58 (1954) 1099-1114.

10. S. H. Page, S. R. Goates, M. L. Lee, J. Supercritical Fluids, 4 (1991) 109-117.

11. M. A. McHugh, and V. J. Krukonis, Supercritical Fluid Extraction: Practice and Principles, Butterworth-Heinemann, Boston (1994).

12. E. M. Russick, and J. H. Aubert, Sandia Report, SAND92-1122, Sandia National Laboratories, Albuquerque (1992).

13. D. A. Loy, G. M. Jamison, B. M. Baugher, E. M. Russick, R. A. Assink, S. Prabakar, and K. J. Shea, J. Non-Crystalline Solids, 186 (1995) 44-53.

14. G. T. Mulhern, D. S. Soane, and R. T. Howe, The 7th International Conference on Solid State Sensors and Actuators, Transducers '93 (1993) 296-299. 


\section{FIGURES}
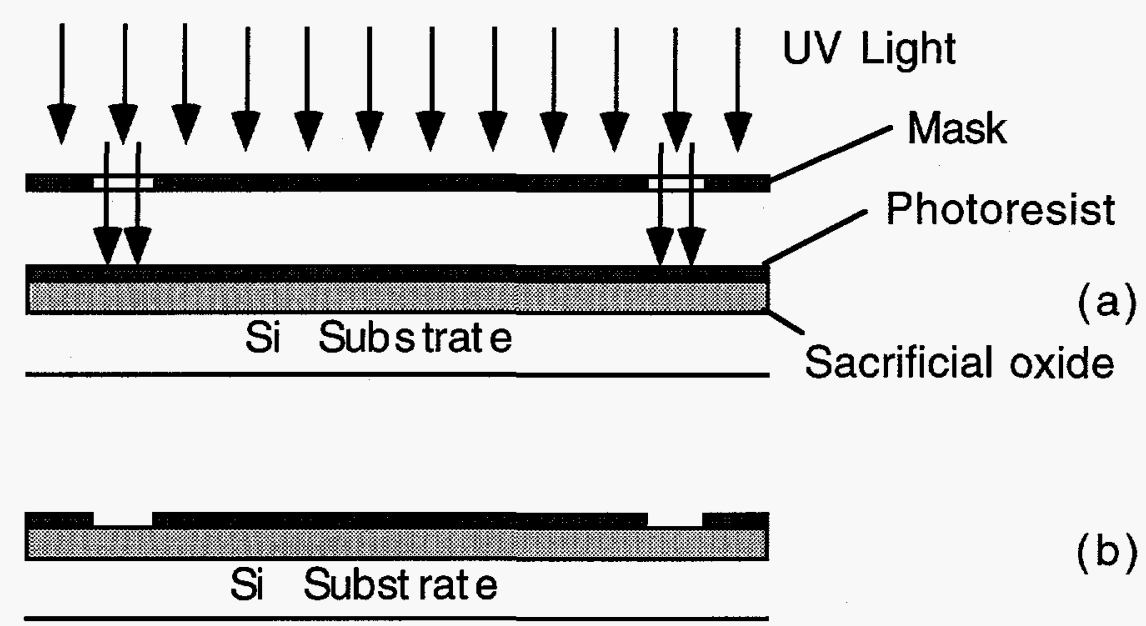

(b)

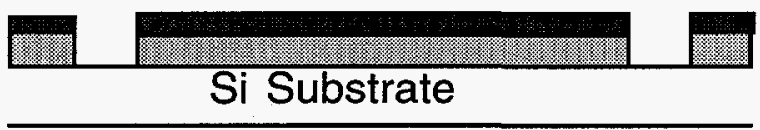

(c)

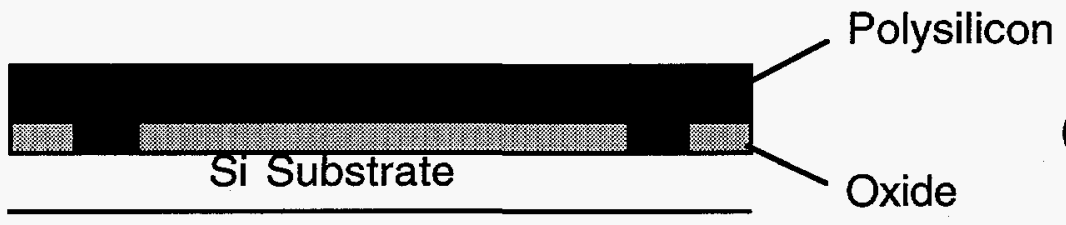

Bridges, pressure sensors:

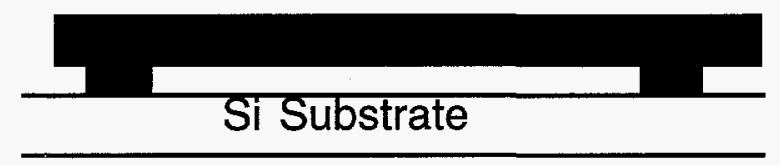

Cantilevers:

(e)

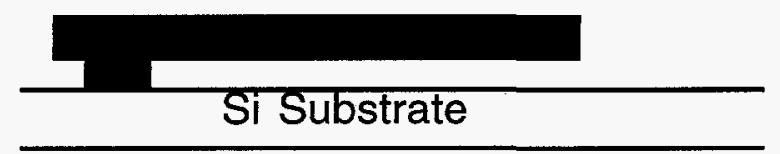

Figure 1 - Diagram representing the basic micromachine etching process. A sacrificial oxide layer and then photoresist are deposited on the silicon wafer, then the photoresist is exposed to UV light through a mask (a). The oxide layer is uncovered in the areas where the photoresist was selectively removed (b). The exposed oxide is removed with a plasma etch (c). The photoresist is removed, then polysilicon is deposited over the remaining oxide (d). The remaining oxide is etched away with HF, leaving the polysilicon on the silicon wafer in the desired configuration (e). 


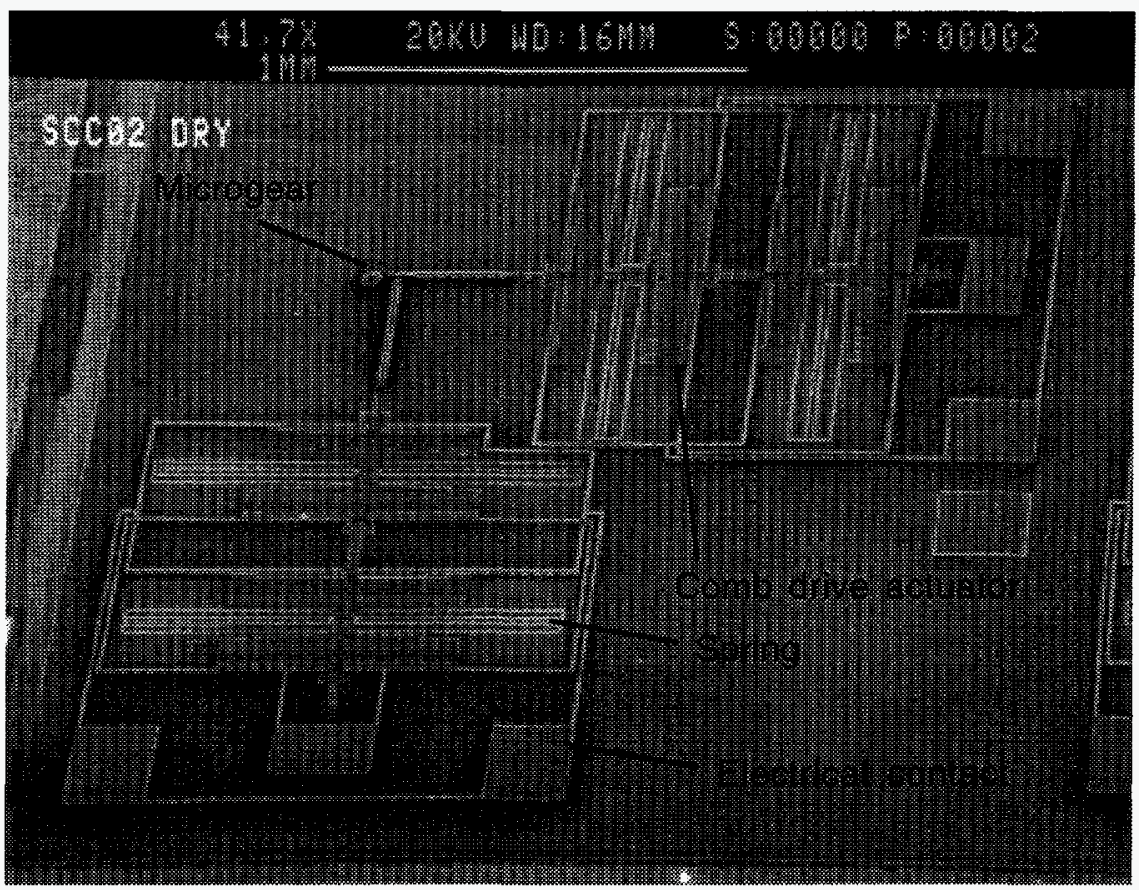

Figure 2 - Microengine, magnified 41.7 times.
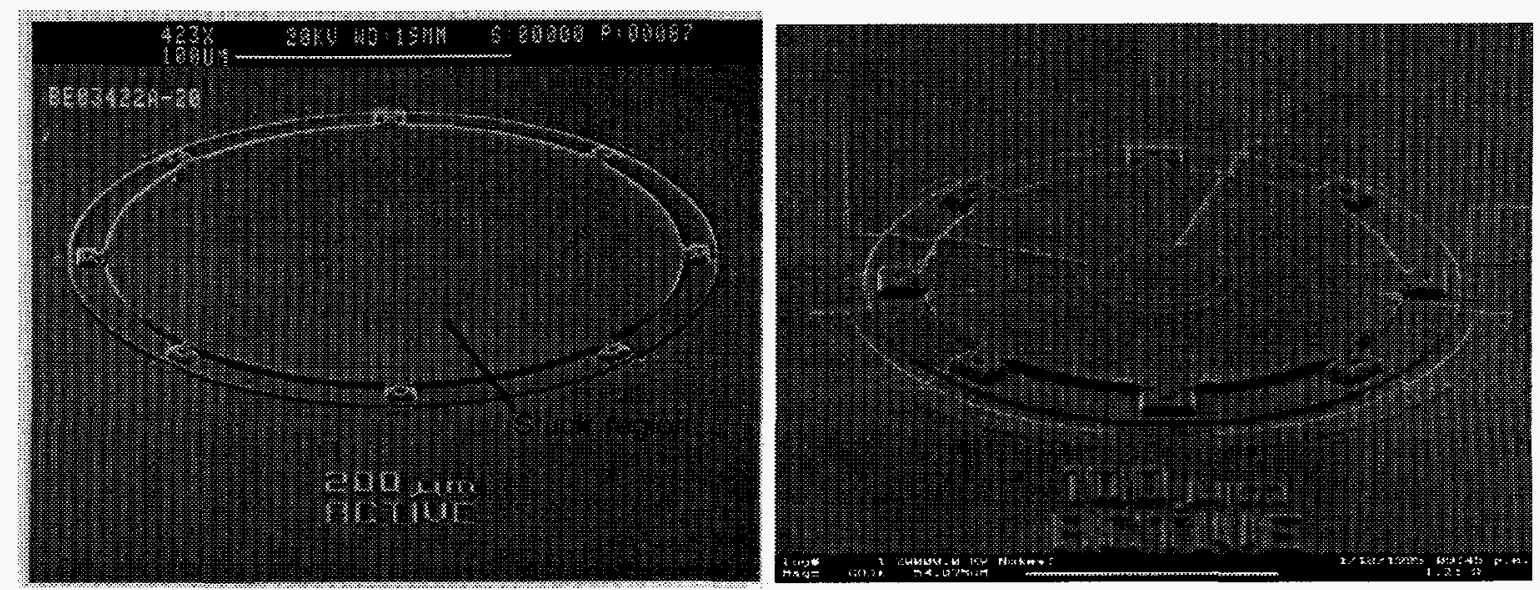

Figure 3 - A stuck $200 \mu \mathrm{m}$ dia. pressure sensor, left (423X), and a fully released $100 \mu \mathrm{m}$ dia. pressure sensor (approx. 700X). 


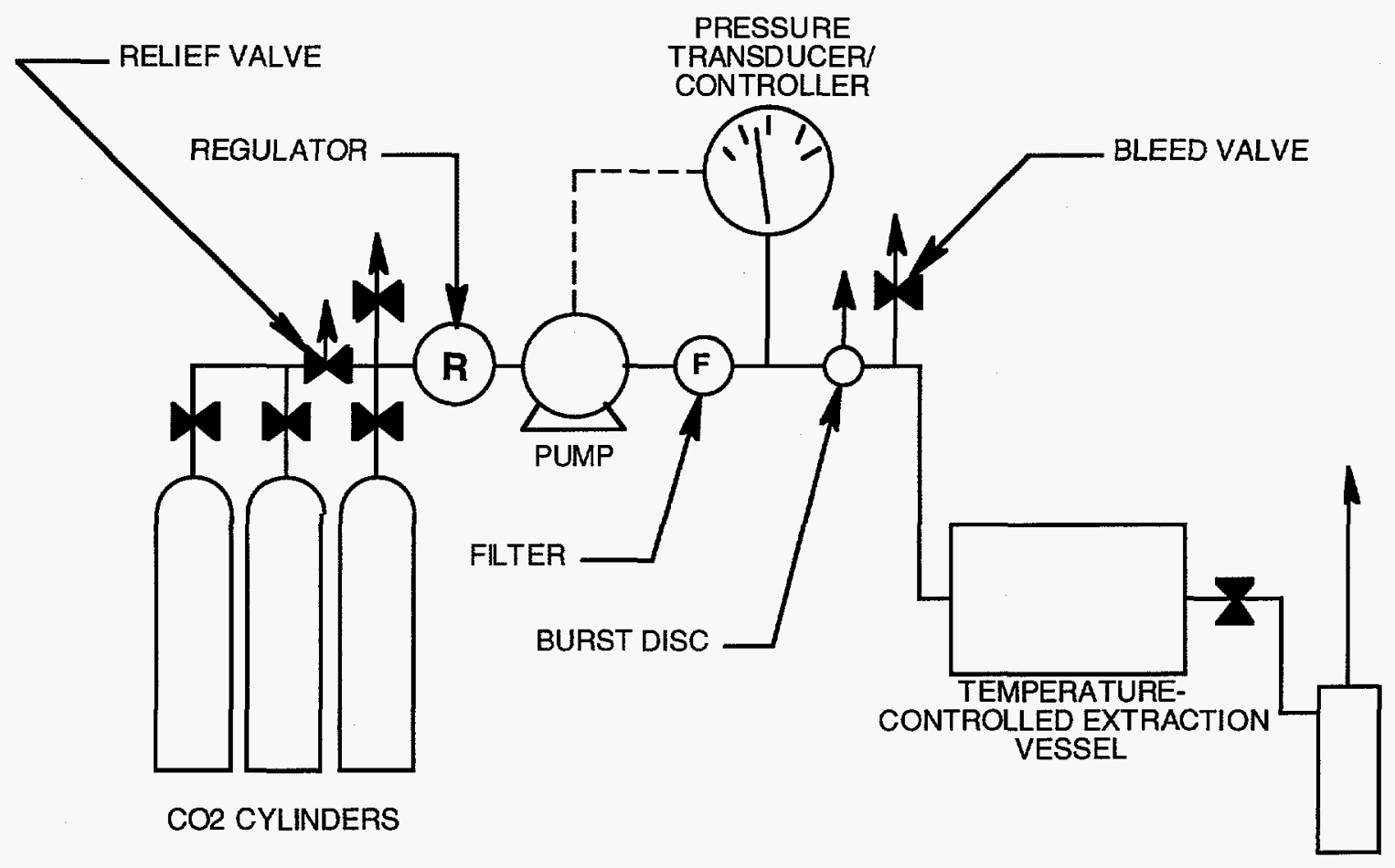

Figure 4 - Schematic diagram of the $5000 \mathrm{psi} \mathrm{CO}_{2}$ extraction system.
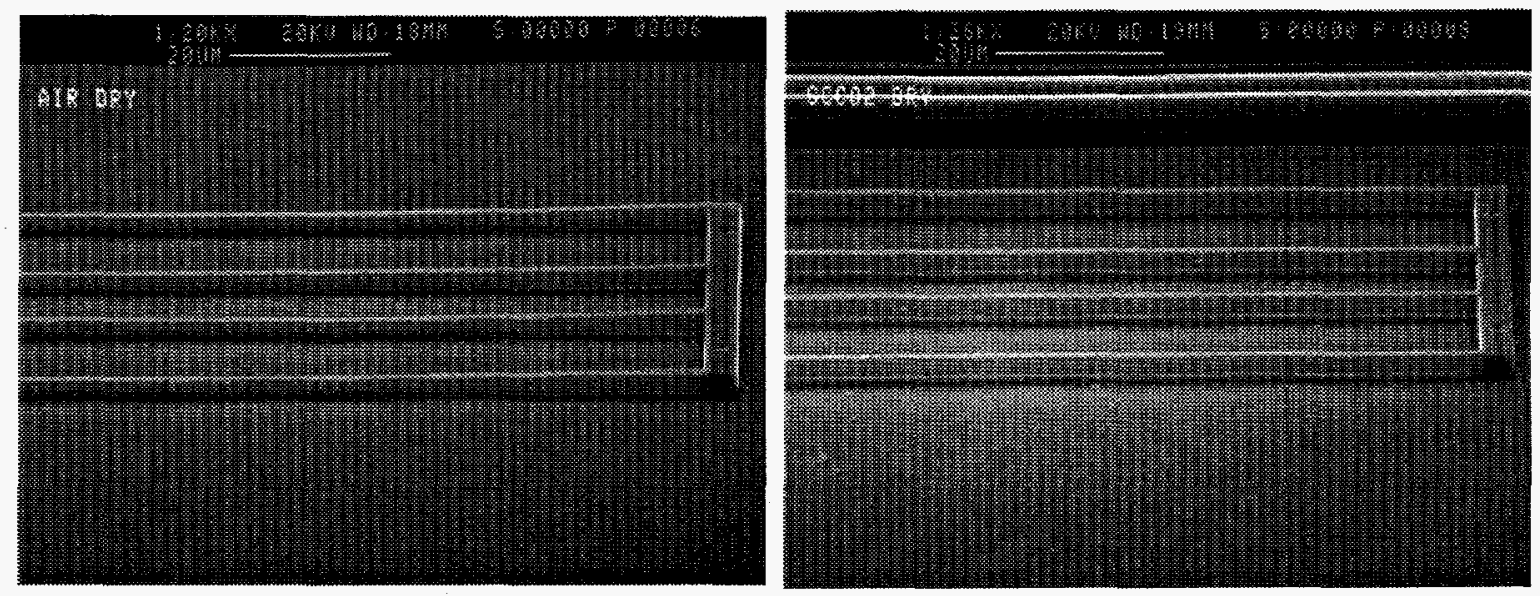

Figure 5 - SEM of a stuck air-dried microengine spring, left (1200X), and that of a $\mathrm{SCCO}_{2}$ extracted spring that is fully released $(1260 \mathrm{X})$. 

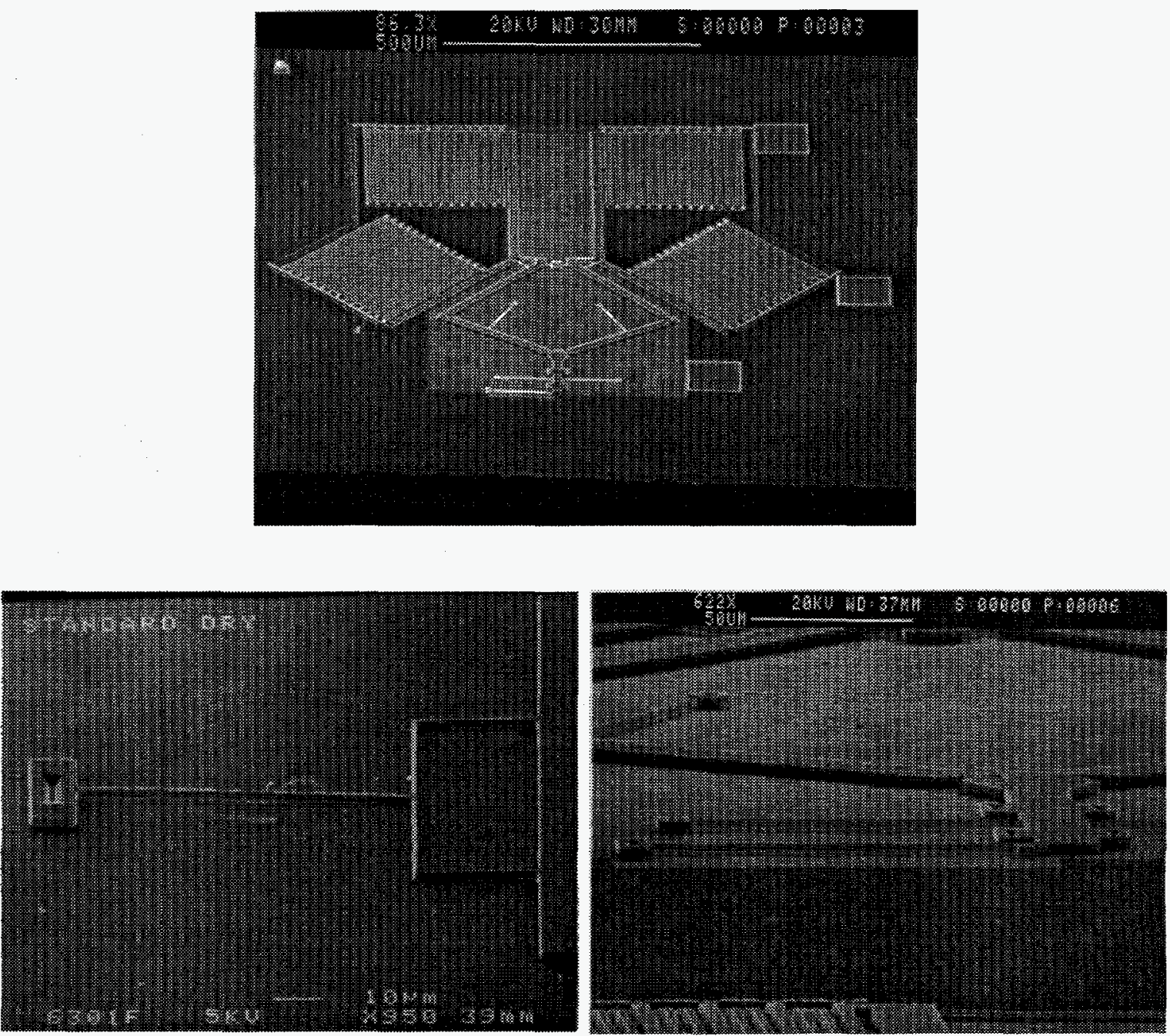

Figure 6 - Micrograph of a microlever, top (86.3X), a stuck air-dried lever arm, left (950X), and fully released $\mathrm{SCCO}_{2}$ extracted lever arms, right (622X). 

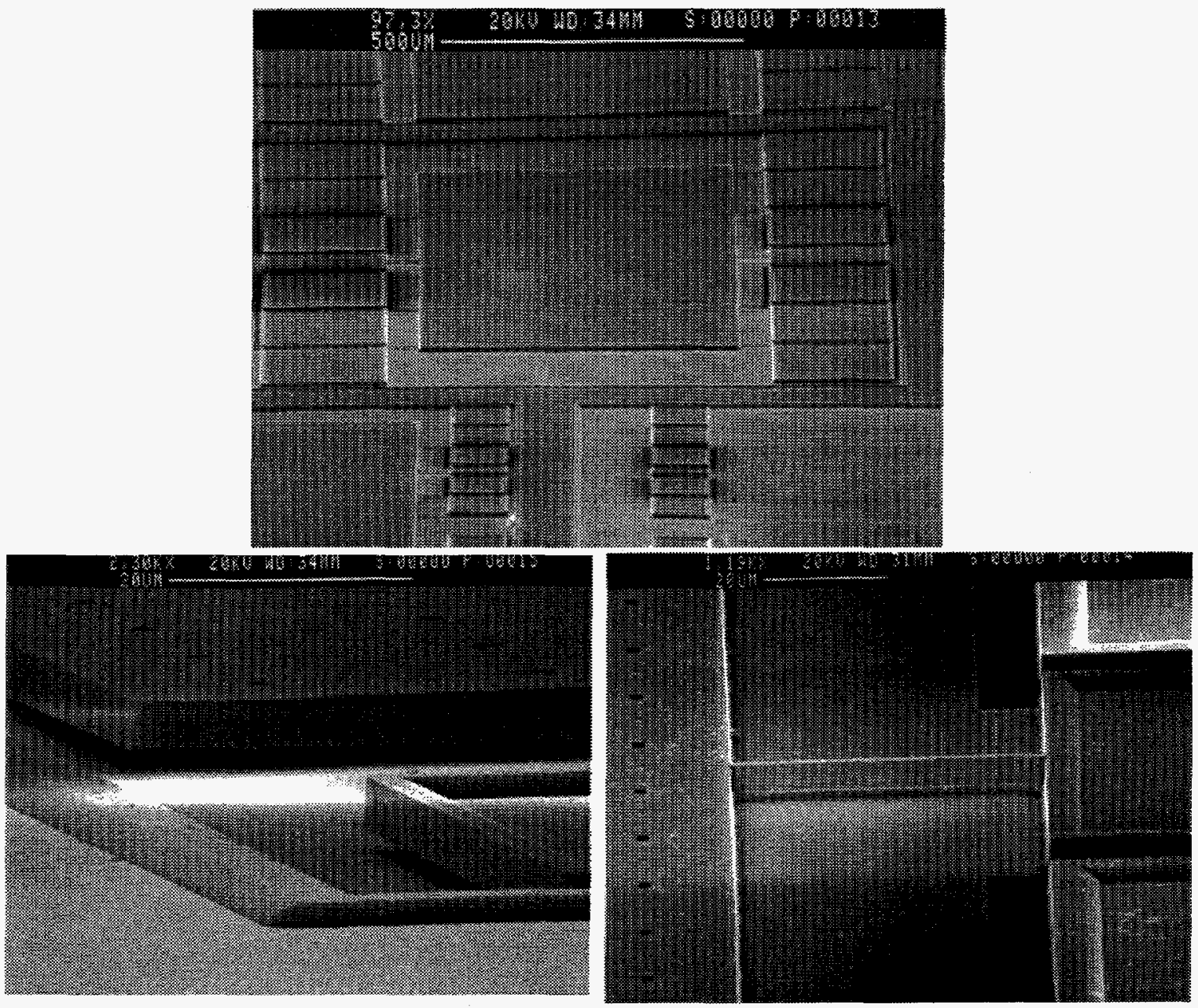

Figure 7 - A micromachined accelerometer, top (97.3X), and close-up views of the accelerometer plate near the substrate, left (2300X), and an accelerometer spring (1190X).
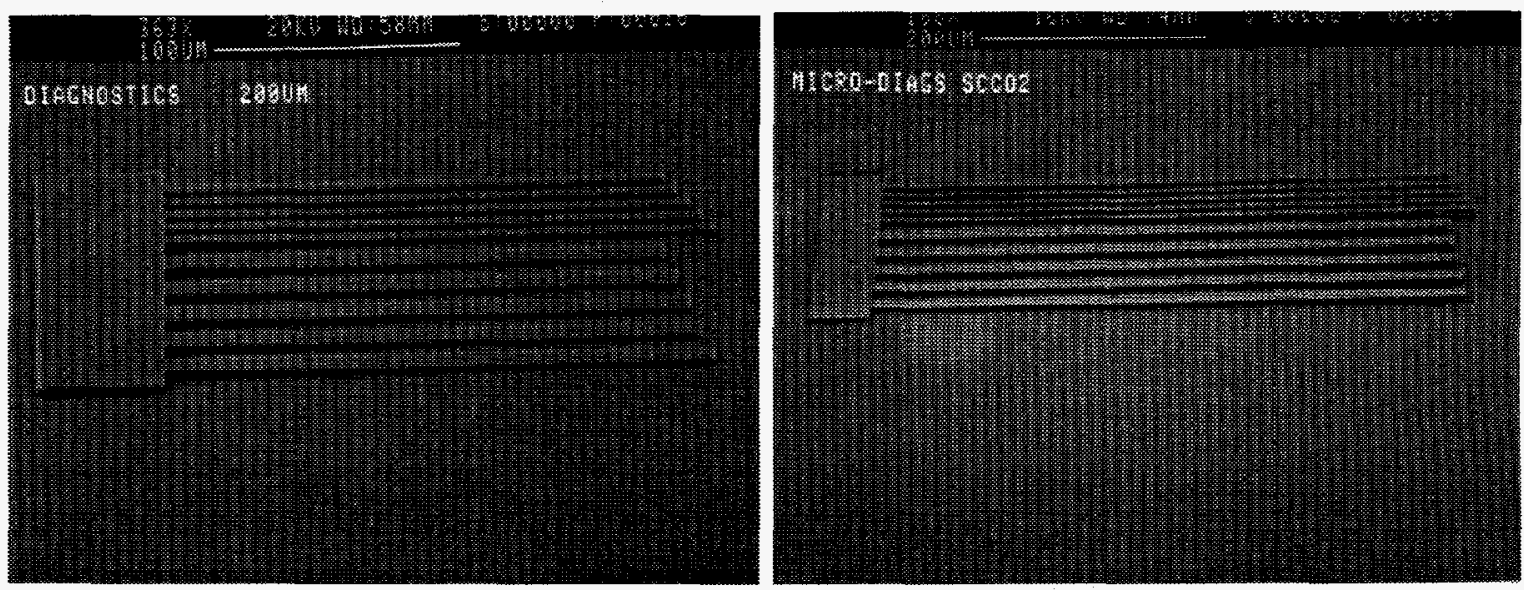

Figure 8 - On the left are air-dried cantlever test structures which have all stuck. On the right are $\mathrm{SCCO}_{2}$ extracted cantilevers which are all released. The shortest air-dried cantilever is $200 \mu \mathrm{m}$ long, and the shortest $\mathrm{SCCO}_{2}$ extracted cantilever is $500 \mu \mathrm{m}$ in length. 